\title{
A Survey on Smartphones Systems for Emergency Management (SPSEM)
}

\author{
Hafsa Maryam \\ Department of Computer Science \\ COMSATS Institute of Information Technology, \\ Islamabad, Pakistan \\ Munam Ali Shah \\ Department of Computer Science \\ COMSATS Institute of Information Technology, \\ Islamabad, Pakistan
}

\author{
Qaisar Javaid \\ Department of Computer Science \& Software Engineering, \\ International Islamic University, \\ Islamabad, Pakistan \\ Muhammad Kamran \\ Department of Distance Continuing \& Computer Education, \\ University of Sindh, \\ Hyderabad, Pakistan
}

\begin{abstract}
Emergency never runs with earlier intimations and indications. In the real world and practical life, detecting and perceiving such emergencies and reporting them are a genuine test and tough challenge. Smartphones Systems for Emergency Management (SPSEM) provide details of existing emergency applications and provide a new direction to overcome the traditional problem having manual intercession and reporting emergencies. In this paper, we provide a comprehensive overview of SPSEM. We elaborate how embedded sensors automate the procedure of emergency crisis detection and responding. Furthermore, we critically evaluate the operations, benefits, limitations, emergency applications and responsiveness in any emergency crisis of different approaches. We provide an easy and concise view of the underlying model adapted by each SPSEM approach. In last, we estimate the future utility and provide an insight of upcoming trends in SPSEM.
\end{abstract}

Keywords-smartphone; emergency response; mobile; crises management

\section{INTRODUCTION}

Emergency never comes with earlier indications in a practical life. It is a real challenge to automatically detect emergency situation and report it to the emergency management. Actually, any crisis management organization either it is private or government sector have a common goal; that is to work on the emergency plans and help those who are in crises. However, there is a big dilemma as complained by many rescue teams that they do not get "the right data in right time". This means that sometimes emergency management teams are unable to get the right data during disaster period. Hence, delay in getting information about crisis in real time leads to delay in rescue process for saving human life. Now-adays due to faster technology, automatic and intelligent systems, human life became comfortable, smartphone is one of such technology that is having different functionalities of user's interests and use.

As per Indian government, department of highway and street transport report during the logbook year 2010, there were around 5 lac street accident occurred in India, which resulted in about 5.2 lac injuries and more than 1.3 lac deaths. About every 4 minutes one street accident happens there. Sadly, more than half of such accidents belong to the age group 25-65 years [1].

In an emergency, an individual who is already in crises could not be in a position to report the emergency to a response team. This is a most helpless situation where affected people need help but they lack ability to search for it. It is believed that using latest tools and technologies such as a smartphone, any disaster or emergency is perceived and automatically reported to an emergency response team. The emergency response team will then be in a position to help individuals in emergency. To accomplish this automated response, we rely on embedded sensor hardware technologies.

The role of smartphone technology in emergency management has greatly improved in tracking emergency zones, and also users can be tracked through enabled GPS. Through Internet connection, users have the ability to send and receive updates related to any disaster situation. Modern smartphones have computational platform with embedded sensors such as location detecting through maps, sensing strength of geomagnetic field. During reporting of disaster information, high power consumption is a major design challenge in the smartphones [2].

\section{A. Modern trends related to Emergency Management in smartphones}

A Wireless Sensor Network (WSN) is basically used in embedded systems. WSN majorly manages short range protocol whereas wireless communication uses long range protocol between two devices for communication [3]. Handheld gadgets like Personal Digital Assistants (PDAs) facilitate users with many useful options like sending or receiving information, playing games etc. When we use different smartphone applications, we use different embedded sensors such as magnetometer, accelerometer; these are directly embedded in our smartphones [4]. Advanced embedded technologies are being introduced recently and different technologies introduced in smartphones can act as a platform for emergency response because of their sensing and data exchange capabilities [4]. A person in crisis is unable to 
report a disaster or emergency incident. If the victim is conscious, he/she can try to escape the crises situation, otherwise, if the victim is unconscious, there should be some mechanism that can automatically invoke, detect the emergency and report it to the response teams. A timely, action and reaction in these situations is a key challenge.

\section{B. Major objectives of SPSEM}

Some of the basic objectives of SPSEM are:

- It automatically detects any disaster by using embedded sensors in the smartphone and then selects an appropriate course of action to help the needy.

- It responds in the time of critical situations by using real time system, right records are sent at right time. Also, the other stakeholders are informed automatically by SPSEM using any sensor(s) and the alerts are communicated through notifications, SMS, email etc.

- It responds in emergency situation with minimal or no human/manual intervention and interaction.

In this paper, we critically evaluate the prospects of smartphones and handheld devices which can respond efficiently and effectively in emergency situations and the emergency management systems/teams could be informed in a timely manner. Furthermore, different user's behavior and thoughts are analyzed in this research paper on the basis of smartphone emergency management applications and the intelligence used by different mobile phones to respond to emergency and crises situation is also a part of this research paper.

The rest of the paper is organized as follows: In Section II, we discuss how smartphone smartly works in any emergency situation and sends response and reports to the crisis/disaster management organization. In Section III, we discuss how social media is used as a tool for communication in crisis or disaster. Section IV describes how smartphones intelligently senses in the real time and takes timely decisions. We elaborate how smartphone works as a cloud server for processing, storing and saving different data and information in Section V. In Section $\mathrm{V}$ we also emphasize on working, behavior and advantages of different emergency applications. The performances of different SPSEM applications are evaluated in Section VI. The future trends about SPSEM are estimated in Section VII. The paper is concluded in Section VIII.

\section{AN EMERGENCY RESPONSE AND SMARTPHONE}

Based on smartphone shipment 2015 release research suggests that for $60 \%$ of all handheld gadgets are smartphones and the numbers are still growing and it is getting more popular among common people [6]. In smartphones, number of emergency applications are available that are beneficial in emergency response. Due to the innovations in GPS technology, this can be very helpful in the tracking of assets and also helpful to send information to emergency management headquarters for the analysis of destruction caused by the disaster [7].

In Bangladesh, a study was conducted about the usage of wireless technology in emergency information system. The results showed that smartphone technology may be used to spread and transmit pre disaster alerts, post disaster declarations and to send/receive data about help needed during the disaster [8]. Additionally, in emergency information administration, geographic location of those in need is very critical. Using mobile phones, destruction locations can either be calculated by using mobile positioning technology or global positioning technology. The satellite positioning mainly based on global positioning system(GPS) and network positioning basically based on the locations of Wi-Fi base stations [9] because this technology uses some nearest locations i.e., station/cell to calculate the position of smartphones thus, the accuracy of mobiles positioning is not as good as that of GPS. Hence, in natural disaster situations, global positioning system (GPS) technology is used because in such situations smartphones can rarely find any Wi-Fi signals [10].

\section{SOCIAL MEDIA: A TOOL FOR CRISES MANAGEMENT}

The popularity of smart phones among common users is increasing gradually. Smartphone shipment data indicates that the growth will increase in coming years [11]. Nowadays, social media is being used as communication tool, platforms such as Facebook, Twitter, and Pinterest etc. enable emergency management systems to communicate instantly with the whole world or public. When it comes to the traditional media forms such as radio, television; managers of emergency management are capable to grasp a large number of audiences to provide updated information when any disaster occurs [12]. Most emergency management organizations use traditional media as well as social media for early warnings, alerts and for interaction and communication with people. In 2012 American Red Cross[13] conducted a survey and found that from out of ten four users use social networks to let family, friends know that they are safe and six percent users have downloaded and installed smartphone emergency applications that could be very beneficial in emergency[14].The limitations and strengths of social media when used as a tool for emergency management as discussed in this paper are summarized in Table 1.

\section{TABLE I. Limitation AND STRENGTH of SOCIAL MEdia: A TOOL For CRises MANAGEMENT}

\begin{tabular}{|c|c|}
\hline Strength of Social Network & Limitations of Social Network \\
\hline $\begin{array}{l}\text { Internet provides reliable connection during any emergency situation. } \\
\text { When telecommunication network fails like earthquake then we use } \\
\text { social media as an alternative option } \\
\text { - Through social media we grasp a broad or wide range audience; } \\
\text { information sharing will spread quickly. } \\
\text { - Social media gives emergency organization to communicate or deal } \\
\text { directly with the users. } \\
\text { - Public can receive up-to-date information with the help of social }\end{array}$ & $\begin{array}{l}\text { Over Social media false or wrong information spread quickly. During } \\
\text { any emergency wrong information creates confusion. } \\
\text { - All people do not use social media properly. Emergency Management } \\
\text { must find another option to communicate with the public. } \\
\text { - In natural disaster electric power may be affected, in this case people } \\
\text { will not be able to charge electronic devices hence, they will not be } \\
\text { able to approach the social network and Wi-Fi. } \\
\text { - During emergency situation users can have non-realistic or artificial }\end{array}$ \\
\hline
\end{tabular}


network in any disaster situation.

- Through social network people listen about disaster news instantly and quickly .People do not have to stay, wait for the traditional media.

\section{SMARTPHONE SENSING AND MOBILE ENABLED DECISIONS}

\section{A. Smartphone/Mobile phone Sensing}

In a research study about uses of smartphones as a tool [15] users have been motivated to use sidewalks to avoid accidents. Users have been appreciated and motivated to inform about structure related problems of sidewalks by taking images with cameras embedded in their smartphones, and then these images get tagged in Google map as an input data for further urban planning in their city [16]. Schoenharl et al [17] developed mobile based wireless emergency response system that is able to monitor real-time geographical and social communication and activity of mobile phone users for recognizing traffic in order to support any crisis event and help destructive planners. A research was conducted in [18] in which smartphone system that supports large scale public events in destruction and emergency situations were investigated in detail.

\section{B. Crowd Sensing}

Crowd sensing can provide us detailed and real-time information about the situation of quickly evolving disaster to promote quick response and resource allocation effectively. Peter Haddawy [19] presents an approach for conditional assessment in crowd sensing for disaster situation. In crowd sensing Peter used mobile 4D smartphone and this mobile 4D was based on emergency alert and information system with conditional awareness information [19]. Mobile 4D is an emergency information system with bi-directional communication. When administration sends alerts, updates then Mobile 4D users receive warnings, alerts on the basis of device locations, Connections can be established through the application and it is also a crowd source system so that users at the ground level are in a position to inform about earthquakes, diseases, floods via smartphone applications, and information is sent over the internet to the administrative level. Mobile 4D is an ideal platform to provide the situation awareness [20].

In March 2014, Flight of the Malaysian Airlines was disappeared [21], through Tomnood system, digital globe posted satellite pictures and asked the users to volunteer for search at any day or time and search imagery zones of the Malaysian plane and tag any related visual like wreckage, As information/request instantly spread across the different platforms of social media, a huge number of people joined the effort. [21].

\section{C. $3 D$ Visualization}

Modern trends towards handheld devices such as Personal Digital Assistant (PDA), smartphones and sensor equipped devices are very important and essential for the Augmented Reality [22]. Advance trends of mobile field systems are dominated by quality control field with no redundant data. The 3D GIS databases contain 3D data structures representing both the geometry and topology of 3D shapes [23]. Visualization uses accurate tracking of mobile systems. The objective is to allow executing "key-hole Surgery" on the underground infrastructure operated by enterprises of the utility sector. In expectations. They can expect instant response about any disaster situation.

- The users need to be literate regarding usage of different forums of social media

order to reduce the risk rate of human life and increase the evacuation speed and rescue can be carried out safely. Emergency responders will soon be testing devices that help in visualizing most of the current floor plans digitally on a mobile device in which an embedded accelerometer can detect the user's organization [24].

\section{Cloud-Computing Mobile-Enabled Judgment System}

Emergency management can take many benefits from Mobile Cloud Computing (MCC) which enables storage and processing to the nearest cloud from smartphone devices [25]. Successful integration of MCC with the emergency organization, it is crucial to deal with the challenges of smartphone and cloud computing. It is very important to notice that a data backup, data redundancy is a part of the emergency management software process selection [26]. In case of a natural disaster, where there is a lot of risk of losing data centers and computers, data should be saved at multiple locations. Backup sites are geographically separate to assure that single crisis or disaster will have no impact on data centers. Natural disaster damages Internet access which makes it very difficult to approach cloud servers, data storage and applications [27].

\section{SMART PHONE SYSTEMS FOR EMERGENCY MANAGEMENT APPLICATIONS}

In this section, we provide some existing emergency applications as an examples of SPSEM. We consider different smartphone operating systems and other hardware support provided by the specific models to support SPSEM. Table 2 presents the comparison of different attributes in SPSEM.

A. All Android base Applications (GPS+All versions from 4.0-5.0+5.1.1)

1) My Disaster Droid:

In 2009, Fajardo and Oppus developed the Disaster Droid (MDD) application [28]. This application calculates the best route for different geographic locations. The calculated route helps the volunteer workers in disaster situation to reach up to maximum number of people in coverage area in best possible time. MDD is an implementation of Travelling Salesman Problem (TSP) and it uses genetic algorithms to generate a solution. In this application geographic locations are described as longitude and latitude. Basically, Disaster Droid shows two views first one is Map View and another one is List View. Map view utilizes the Google Maps to show the location map, while the list view displays the information regarding people in need as a list, this list also contains the corresponding location and distance. In calculating the optimum route along various geographical locations the application assumes geographic locations as cities and the rescuers as the travelling salesmen [28].

\section{2) Smart Rescue:}

The basic notion of Smart Rescue is to use smartphone technology to assist in delay phase in the initial crisis times [29]. Smart Rescue technology maps threats and help people in 
the case of emergency. If many smartphones are sensing the environment surrounding the people then those phones are used as input sources for getting threat pictures and allow and inform people to take necessary actions to avoid any hazards in the affected area [29]. The SR exploits the following objective.

- The sensor can be used to map crisis using active human-centered sensing, as a crowd sensing, thus providing the potential for environment exhaustive exploration.

- It can carry complicated tasks without draining the battery quickly and without affecting the functionality of smartphones for normal use.

- Smart Rescue supports activity recognition via sensors

3) The Wreck Watch:

When android users install this application on their smartphone devices, it effectively and efficiently integrates their mobile devices in to the sensor wireless network; this wreck watch network is also called "Smart Net" [30]. Application provides many user benefits, and it permits user to save emergency contacts on HTTP server. When collision detected, user's emergency contacts can be informed of the emergency, accident via email, SMS. Automatic data sharing can permit responder more time to analyze the accident situation rather than updating the contacts about the situation. Another feature of this application is that a user can view the location of other wreck watch users, these features permit users to find route/path. Application user selects a marker map by tapping on specific marker. This selected option opens another menu that permits user to upload new media and this feature was only associated with the wreck watch [31].

4) Detection Smoke system:

Detector smoke system is an emergency or disaster application system that is useful in case of high flames like fire. Such types of detectors are used widely in mechanical and manufacturing factories and also used in personal and public places like, shopping malls, conferences and different public gathering areas. These detector systems in case of fire either respond and/or report emergency or disaster to central fire alarm system or alert public with some kind of audible alarm. These handheld gadgets are available and accessible in different shapes depending upon need or requirement. The older detectors were using physical ionization process whereas advanced technology utilizes the photoelectric diodes to sense the smoke in atmosphere or air. The application is used by the production or manufacturer houses to detect smoke/fire to figure out the disaster or emergency in effective and efficient manner [32].

5) First Aid Application (FA):

FA is developed to give some preliminary instructions for taking care of users in Android smartphones; basically navigation system uses Google API (maps) for searching an appropriate or suitable way or path to the nearest hospital. In the case of any emergency this function is activated on user's smartphone to navigate victims through the shortest path to the hospital [33]. This application gives some useful instructions or precautionary measures about taking initial care of the patients before sending them to the doctors or hospitals. The application also provides the functionality of searching and finding the nearest doctor's clinic or hospital. This application provides two types of services, first one is different sets of first aid guidance and second one is finding the accurate, appropriate and suitable hospital to go. In first service, i.e., the first aid guidance service includes the information regarding muscles, skin, or material injuries. In second service in case of emergency or disaster condition, if a patient wants to go to the nearest doctor or hospital then this application provides functionality of searching and finding, navigating or directing to the accurate, appropriate nearest clinic or hospital for patient, and the searching current location functionality starts by using smartphone's global positioning system and then this application will ask from the patient for radius searching and at last but not least most appropriate directions to the selected clinic or hospital will be provided and it appear as an output or result.

\section{6) Fire Ready $(F R)$ :}

FSC (Fire Service Commissioner) has launched the fire ready application in 2013. FR application is the official Victoria government app for Country Fire Authority (CFA), Metropolitan Fire Bridge (MFB) and Department of environment, Land, Water, Planning (DELWP). This fire warnings and information system, notifies users of fire dangers in affected area and sends photographs of bushfire activity. Application is managed by Victoria emergency management on behalf of the fire agencies, supported by the department of Justice and Regulations [34]. User must create a zone in order to receive specific location notifications on a user's device when incident occurs. Warnings are issued by emergency service to provide advice to the public and such information displays on the application, these warnings can include advice, watch act etc., and emergency warnings are only available on the application while they are relevant to a fire or incident [35]. On the map, warnings are placed on different locations surrounding the fire; the specific advice is also given for all affected location(s) as to how the fire may affect them.

\section{B. All Smartphones(GPS)}

\section{1) Great Call:}

Great Call application gives you authentic and easy-touse/comfortable wireless service, this wireless system is very similar to traditional cellphones but it is only one button gadget. Great Call is the most utilized service in which any individual if is in disaster or emergency situation can communicate with representatives of the service directly upon pressing the button for help. The main feature of such service is having quick or instant response on call from trained and expert agent. In US this is mostly utilized as personal advisable device [36].

\section{2) Quake SOS:}

Quake SOS is the first app, designed for natural disaster emergency, Combination of an emergency alert system for earthquake information and SOS call for victims. The application allows to provide user's option that if user is in an earth quake then he can notify to the contacts that either he is safe or needs help. Quake SOS contains useful information including an earthquake database, if user launches this app in his/her smartphone, the application automatically update itself 
every time and also provides information such as when and where earthquakes have occurred [37].

\section{3) Saper:}

Saper is basically an explosive detection application for smartphones. The word Saper is a Polish term for "mine sweeper", at the same time acronym for "Sensor Amplified Perception for Explosive Recognition". The application exploits the built-in magnetometer used in smartphones for compass like functionality. The application detects and works on small disturbances in the magnetic field around an explosive material. The application is connected to a cloud-based server and compares the recorded magnetic disturbance information to the information place in database for identifying the explosive [38].

\section{4) Federal Emergency Management Agency (FEMA):}

FEMA application contains awareness information about different kinds of emergency situations and disasters. The application has an interactive checklist for emergency kits, and a section plan for emergency meeting locations. FEMA basically is used for emergency awareness and preparation that what are the general ways the public can adopt pre and postdisaster. Disaster report features enable citizens to share GPS photos from the disaster area. This application uses social media to send alerts via status or email alerts to warn public of imminent threats. A study commissioned by the American Red Cross found that roughly $50 \%$ of the respondents would text for alerts, email for emergency information and help public during emergency situations [39].

\section{5) Elerts Application:}

Elerts applications are widely used in USA. The application system is centralized and used as a web and application format, Using Elert application the individual who is in emergency or disaster site can take snapshots of it, which are automatically uploaded to central website and on the other side another user of same application gets the alerts, warnings regarding such disaster, emergency along with geographic locations and images [40]. The highlights of Elerts application are provided below:

- Bi-directional communication: Once client or user gets warning or alert message on his/her cellphones, they can also reply back with other detail or elaborate information regarding disaster. Emergency teams or any other volunteers give or suggest advice or direction to get rid of emergency situation.

- Reports: Every user who has smartphone and use this application through installation on mobile phone can send direct report or response to others.

- Photos: Sharing live snapshots or images with personal security or any other user supported by alert application is a great feature.

- GPS and Mapping: Utilizing latest and advanced technology like Google Maps, through this Elert application locates the disaster place and suggest or advice others to address the issues with the details of locations.

\section{6) Automatic Crash Notification (ACN):}

Christopher Thompson presented another innovative application that is Automatic Crash Notification system. The aim or objective of this application is to save lives by reducing or decreasing time required for disaster or emergency teams to arrive to victims. ACN sensor network in automobiles is used to detect car accidents, it also communicates with a checking or monitoring station through radio cellular network. Sensor gadgets provide useful information to detect auto car destruction. Wreck watch server utilize ACN system to detect car accidents that are displayed on smartphone devices and the user is instantly allowed to access accident information through webpage [41].

\section{Adhoc-Network (iPhone)}

1) Help Me:

This is very important and interesting application that deals with emergency environment called, Help Me [42]. This application exhibits, introduces another good approach by using Ad-hoc network to communicate during emergency times. It would work without any help of telephone cellular network and forwards the message very smartly on the basis of hop-to-hop. It is also capable of making decision on the basis of routing algorithm to forward any message further. Help Me server is basically centralized to record all happening events about any disaster or emergency, once service is re-established or restored. This information is very helpful from smartphone that could also tell about the missing persons if such thing happens.

\section{Web Based Collaboration tool}

\section{1) Sahana Foss:}

The Sahana is an open source and free disaster system, based on web collaboration tool. It is a pluggable, web-based disaster management solution that provides optimal solutions caused by the disaster and it is also designed to help during the disaster relief phases. Current disaster system will aid in the response phase during the disaster. In this phase time quality is very important. A seconds' delay may cost someone's life. System determines the most optimum route for the rescuers in order to serve huge amount of people and provide maximum coverage of affected area in shortest time. [43].

\section{E. WSN (Wireless Sensor Network)}

\section{1) Closed Circuit TV (CCTV):}

CCTV basically is the utilization of cameras and wireless network to transfer a signal to its scanning box. This is not the similar to the television we have. It can be located as point to different locations or point to same location and comprises of monitoring and camera sets. These are majorly used in banks, airports, stores and clubs [44]. In manufacturing and mechanical plant, these camcorders or video cams are used to observe, scan and point to take accurate decisions while one just sitting in control room. They are also used at some other places like generation of heavy heat rooms while metal molding or other such type of areas where employees cannot sustain environments then such CCTVs are more beneficial and advantageous. A CCTV operates for a time being or continuously monitors a particular situation. Nowadays, we have advanced forms of Digital Video Recorders (DVRs) 
which offer flexibility and adaptability to record or monitor 24 by 7 for up to two years. DVRs frequently capturing video and record it to some disk or tape like storage. Also, CCTV has some great features like detection of faces and motion, scanning, monitoring to image processing [44].

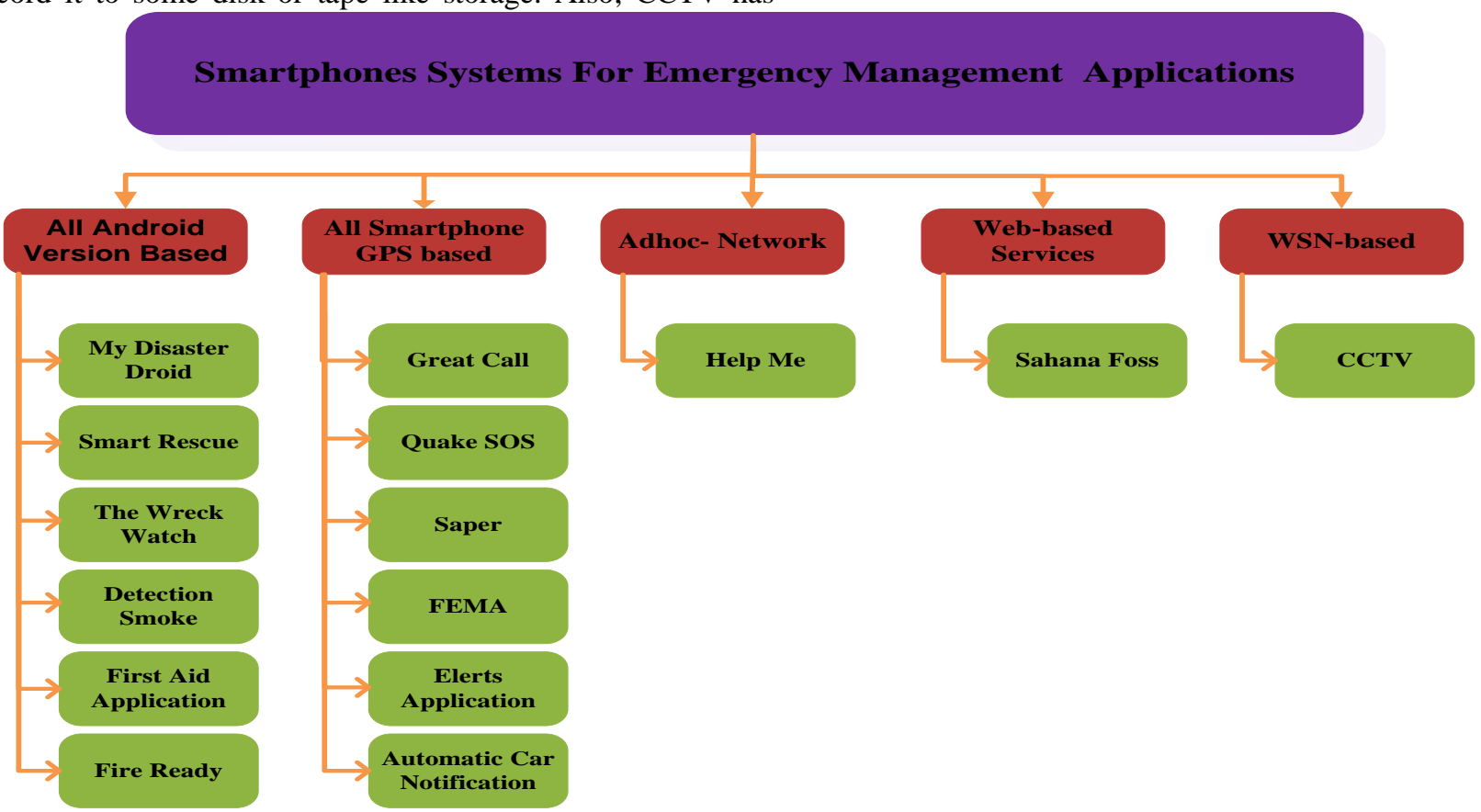

Fig. 1. Taxonomy of Smartphones Systems for Emergency Management Applications

\section{PERFORMANCE EVALUATION OF SPSEM}

We have performed detailed performance evaluation of the existing emergency applications of Smartphones Systems for Emergency Management by using different smartphone system features. We analyzed the behavior of Smartphone Systems for Emergency Management applications feature attributes like performance, availability etc. and the performance comparison of the approaches that we have discussed so far in this paper is given in Table 2. On the basis of the above discussed platforms the features we have identified and highlighted with major limitations and benefits of the Smartphone System for Emergency Management Applications are given in Table 3.

TABLE II. COMPARISON OF THE ATTRIBUTES OF SPSEM APPLICATIONS

\begin{tabular}{|c|c|c|c|c|c|c|c|c|}
\hline $\begin{array}{l}\text { Categorization } \\
\text { Of Different } \\
\text { Platforms }\end{array}$ & $\begin{array}{l}\text { Emergency } \\
\text { System } \\
\text { Application }\end{array}$ & Platform & Availability & Interoperability & Performance & Reliability & Portability & Usability \\
\hline \multirow{6}{*}{$\begin{array}{l}\text { ALL ANDROID } \\
\text { VERSIONS } \\
\text { FROM } 4.0- \\
\mathbf{5 . 0 + 5 . 1 . 1}\end{array}$} & $\begin{array}{l}\text { My Disaster } \\
\text { Droid }\end{array}$ & Android & Yes & Yes & Best & Good & - & Yes \\
\hline & Smart Rescue & $\begin{array}{l}\text { Android } 4.0 \\
\text { and above }\end{array}$ & Yes & Yes & Better & Good & Yes & Yes \\
\hline & $\begin{array}{l}\text { The Wreck } \\
\text { Watch }\end{array}$ & Android & Yes & Yes & Better & Bad & No & Yes \\
\hline & $\begin{array}{l}\text { Detection } \\
\text { Smoke }\end{array}$ & $\begin{array}{l}\text { Detection } \\
\text { Smoke } \\
\text { Android }\end{array}$ & Yes & No & Good & Good & No & No \\
\hline & $\begin{array}{l}\text { First Aid } \\
\text { Application }\end{array}$ & Android GPS & Yes & Yes & Good & Good & No & Yes \\
\hline & Fire Ready & $\begin{array}{l}\text { Fire } \\
\text { detection } \\
\text { Android } \\
\text { based }\end{array}$ & Yes & Yes & Better & Bad & No & Yes \\
\hline \multirow{2}{*}{$\begin{array}{l}\text { ALL } \\
\text { SMARTPHONE } \\
\text { GPS BASED }\end{array}$} & Great Call & $\begin{array}{l}\text { All } \\
\text { Smartphone } \\
\text { GPS }\end{array}$ & Yes & No & Good & Bad & No & No \\
\hline & Quake SOS & $\begin{array}{l}\text { All } \\
\text { Smartphone } \\
\text { GPS+ } \\
\text { IPhone }\end{array}$ & Yes & Yes & Good & Good & - & Yes \\
\hline
\end{tabular}




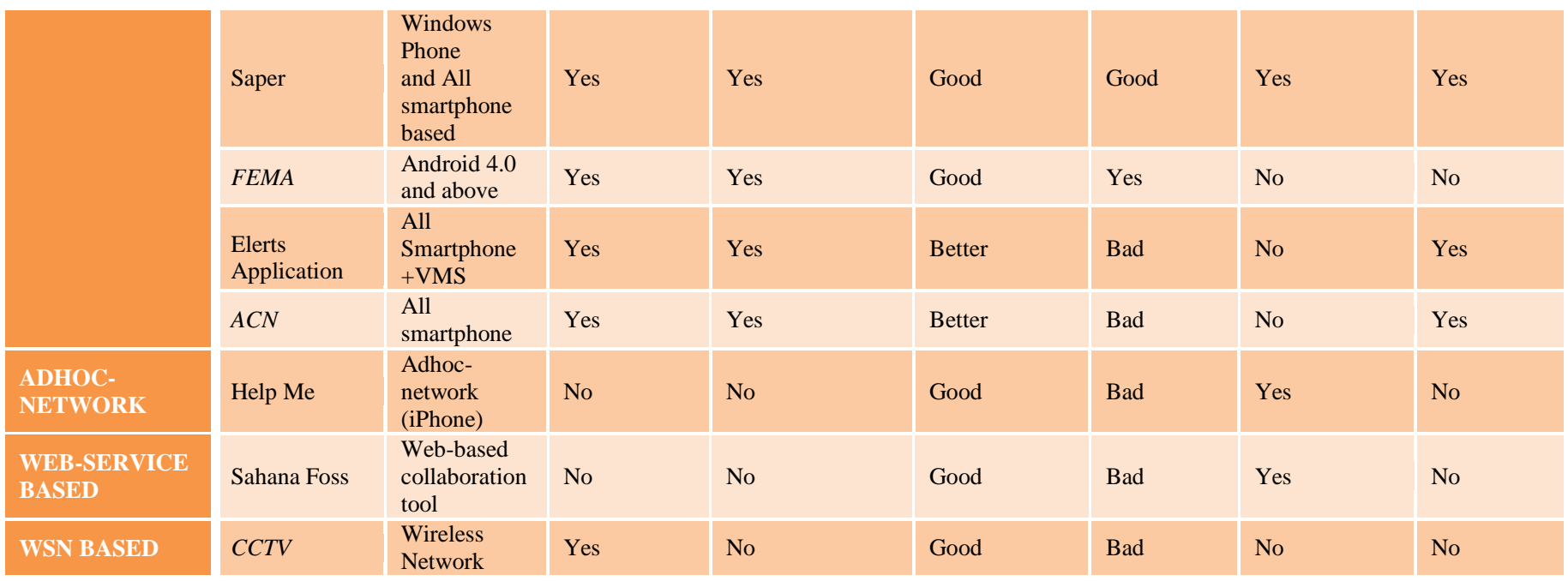

TABLE III. PERFORMANCE COMPARISON OF SPSEM BENEFITS AND LIMITATIONS

\begin{tabular}{|c|c|c|c|c|}
\hline $\begin{array}{l}\text { Categorization } \\
\text { of Platform }\end{array}$ & $\begin{array}{l}\text { Application } \\
\text { Smartphone }\end{array}$ & $\begin{array}{l}\text { Version } \\
\text { Launche } \\
\text { d year }\end{array}$ & Benefits & Limitations \\
\hline \multirow{6}{*}{$\begin{array}{l}\text { ALL ANDROID } \\
\text { VERSIONS } \\
\text { FROM 4.0- } \\
\text { 5.0+5.1.1 }\end{array}$} & $\begin{array}{l}\text { My Disaster } \\
\text { Droid }\end{array}$ & 2009-10 & $\begin{array}{l}\text { - Using user's smartphones in any disaster } \\
\text { location can be detected using GPS and also } \\
\text { calculating the distance between different geo } \\
\text { locations. }\end{array}$ & $\begin{array}{l}\text { - All people can't be attended at once because of limited } \\
\text { resources and database. } \\
\text { - Prioritization is one the general issue. }\end{array}$ \\
\hline & $\begin{array}{l}\text { Smart } \\
\text { Rescue }\end{array}$ & 2012 & $\begin{array}{l}\text { This application provides a great sense of } \\
\text { security to children, girls and women's. Provide } \\
\text { the feature of video call in which the user can } \\
\text { explain the current condition and location of } \\
\text { any emergency. }\end{array}$ & $\begin{array}{l}\text { - Updating, redesigning the databases so we can see the } \\
\text { related or relevant information for emergency situation } \\
\text { - When the information mix with the sensor network of } \\
\text { low pixels ordinary hazards pictures not executed. }\end{array}$ \\
\hline & $\begin{array}{l}\text { The Wreck } \\
\text { Watch }\end{array}$ & 2013 & $\begin{array}{l}\text { Wreck watch provides different functionality } \\
\text { like data recorder related to any event by } \\
\text { recording the track and also declare emergency } \\
\text { responses of any accident through images, } \\
\text { video. }\end{array}$ & $\begin{array}{l}\text { - It may not be conceivable to perceive all difficulties } \\
\text { with smartphone. } \\
\text { - Smart phones can surpass the convenience of } \\
\text { customary in-vehicle accident ID systems. }\end{array}$ \\
\hline & $\begin{array}{l}\text { First Aid } \\
\text { Application }\end{array}$ & 2013 & $\begin{array}{l}\text { - Interactive tests to allow you to discover that } \\
\text { you can share with your companion about } \\
\text { lifesaving knowledge [45]. }\end{array}$ & $\begin{array}{l}\text { - This application is no substitute for medical treatment. } \\
\text { - Application based on limited case or first-aid scenarios. }\end{array}$ \\
\hline & $\begin{array}{l}\text { Detection } \\
\text { Smoke }\end{array}$ & 2014 & $\begin{array}{l}\text { - This system id used to detect fire or high flames } \\
\text { disaster through some audible and noticeable } \\
\text { alarm. }\end{array}$ & $\begin{array}{l}\text { - Definite events are not being recorded. } \\
\text { - Neglectful or physical disable person won't able or } \\
\text { agreed to respond, even this system attentions by strong } \\
\text { audio signals. }\end{array}$ \\
\hline & Fire Ready & 2014 & $\begin{array}{l}\text { In this we can watch or view rating of current } \\
\text { fire danger in map and total fire status, GPS } \\
\text { integration to detect location and surrounding } \\
\text { events or happenings. }\end{array}$ & $\begin{array}{l}\text { - This application sometime did not give correct } \\
\text { information. } \\
\text { - This application was not working on the IPhone } 4 \text { and } \\
\text { some IPads [46]. } \\
\text { - Sometime application is running slow when millions of } \\
\text { users use this application. }\end{array}$ \\
\hline & Great Call & 2009 & $\begin{array}{l}\text { This application is mostly used as a specific } \\
\text { person device and urgent response with trained } \\
\text { person is main key feature of such services. }\end{array}$ & $\begin{array}{l}\text { - Crisis or emergency is not detected, or investigate } \\
\text { automatically. } \\
\text { - Emergency should be responded by a person who is in } \\
\text { disaster, crises or emergency. }\end{array}$ \\
\hline & Quake SOS & 2014 & $\begin{array}{l}\text { This app provides latest news and information } \\
\text { about earthquake and also provides real-time } \\
\text { quake disaster information for example } \\
\text { Tsunami. }\end{array}$ & $\begin{array}{l}\text { - Cannot detect adware samples. } \\
\text { - QUAKE SOS required signal for work. } \\
\text { - Signal requirement certainly pose a problem } \\
\text { depending on the situation. } \\
\text { - Smaller earthquakes won take out satellite towers and } \\
\text { internet signals but longer one certainly could, In that } \\
\text { case, no information could be sent or gathered [47]. }\end{array}$ \\
\hline
\end{tabular}




\begin{tabular}{|c|c|c|c|c|}
\hline $\begin{array}{l}\text { ALL } \\
\text { SMARTPHONE }\end{array}$ & Saper & 2012 & $\begin{array}{l}\text { - This application is used to detect explosives and } \\
\text { also measures around } 30 \mathrm{~cm} \text {.potential risk and } \\
\text { explosive material. } \\
\text { - SAPER includes external wireless } \\
\text { magnetometer and also allow for the remote } \\
\text { detection [48]. }\end{array}$ & $\begin{array}{l}\text { - Saper is not intended to replace explosive detection and } \\
\text { mine swapping technology but it provide only } \\
\text { additional help when none are available. } \\
\text { - Limited databases in the sense of comparison. }\end{array}$ \\
\hline \multirow[t]{3}{*}{ GPS BASED } & FEMA & 2009 & $\begin{array}{l}\text { - FEMA app facilitates the user with emergency } \\
\text { helpline number, latest information related to } \\
\text { before, after and during any crisis and } \\
\text { emergency situation. }\end{array}$ & $\begin{array}{l}\text { - Imbalance of focus between homeland security and } \\
\text { natural disaster management [48]. } \\
\text { - Challenge of involving public in preparedness } \\
\text { planning. }\end{array}$ \\
\hline & $\begin{array}{l}\text { Elerts } \\
\text { Application }\end{array}$ & 2013 & $\begin{array}{l}\text { - Use Security Distance Model to measure } \\
\text { dangerous level due to combination of } \\
\text { requested permissions. }\end{array}$ & $\begin{array}{l}\text { - Any disaster or emergency must be seen and reported } \\
\text { by first responder, and automatically emergency not be } \\
\text { detected. }\end{array}$ \\
\hline & $\mathrm{ACN}$ & 2014 & $\begin{array}{l}\text { - Smartphone can surpass the usefulness and } \\
\text { helpfulness if vehicle has ACN framework. }\end{array}$ & $\begin{array}{l}\text { - No experimental examination in genuine accident } \\
\text { situations. }\end{array}$ \\
\hline $\begin{array}{l}\text { ADHOC- } \\
\text { NETWORK }\end{array}$ & Help Me & 2012 & $\begin{array}{l}\text { - This application is very helpful and intended to } \\
\text { recognize missing or misplaced person through } \\
\text { stored information in user's mobile device. }\end{array}$ & $\begin{array}{l}\text { - Restrictedly depend on created ad-hoc network near or } \\
\text { close by. } \\
\text { - It's may not be suitable for personal emergency where } \\
\text { a common man can stay alone like handicap adults or } \\
\text { old-age citizen. }\end{array}$ \\
\hline $\begin{array}{l}\text { WEB BASED } \\
\text { SERVICE }\end{array}$ & Sahana Foss & 2006 & $\begin{array}{l}\text { - The response stage unites or consolidates with } \\
\text { rescue operations for the obtainment of } \\
\text { emergency help; in emergency situation } \\
\text { efficiency is very important. }\end{array}$ & $\begin{array}{l}\text { - The present disaster organization system does not } \\
\text { coordinate with handheld gadgets or device that will } \\
\text { help in the response stage in disaster. }\end{array}$ \\
\hline WSN BASED & CCTV & 2007 & $\begin{array}{l}\text { - Recorded features or images needs to be } \\
\text { governed by executive to know any kind of } \\
\text { unusual conduct. }\end{array}$ & $\begin{array}{l}\text { - CCTV is utilized for observing or monitoring and not } \\
\text { for crisis reporting. }\end{array}$ \\
\hline
\end{tabular}

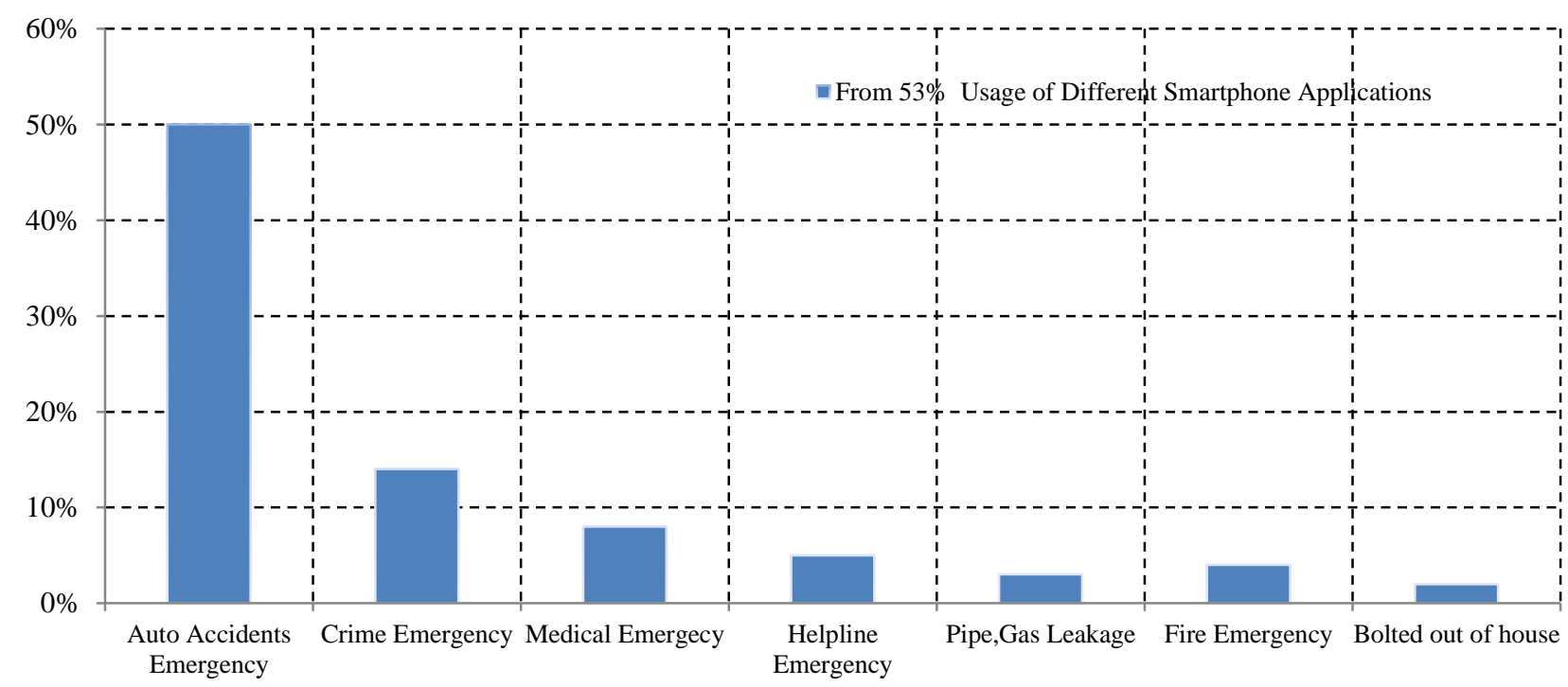

Fig. 2. Conducted by American Research and Audit center about from 53\% usage of different Smartphones Emergency Applications

Through a critical examination of American research and audit center and various survey papers till 2014-2015, it is concluded that $60 \%$ of young owners use their smartphones as an instrument for emergency circumstances in which 53\% energetic proprietors use emergency applications and rest of the young proprietors use contact numbers of their family, mates and most of them without using any emergency application use social media platforms through notifications irrespective of whether they are safe or not, resolve or get rid from emergency situations, conditions or circumstances by using smartphones this is in line with the findings in [49]. In a survey presented in [49], 50\% users including auto accidents use their smartphones in emergency situations and $14 \%$ use their smartphones in any disaster or emergency, through handheld gadgets they notify the emergency management authorities to get help, $8 \%$ use their smart phones for medical emergency 5\% use their phones for emergency helpline like 911 or HELP ME emergency app and 3\% user use fire, gas application, they found it very useful in an emergency situation, also shown in Figure 2. Another assessment survey was conducted in Japan in 2013 2014 [50] to investigate how many people rely on 
smartphones emergency applications. Some interesting facts were revealed which are provided in Table 4 and Figure 3.

TABLE IV. SURVEY HELD IN JAPAN RELATED TO RELIABILITY OF SMARTPHONE APPLICATIONS

\begin{tabular}{|l|l|}
\hline Assessment of Emergency app & $\begin{array}{l}\text { \%age analysis of emergency } \\
\text { applications }\end{array}$ \\
\hline Reliable & $58 \%$ \\
\hline Doubtful Situation & $30 \%$ \\
\hline Strongly Reliable & $8 \%$ \\
\hline Not Reliable & $4 \%$ \\
\hline Strongly Not-reliable & $0 \%$ \\
\hline
\end{tabular}

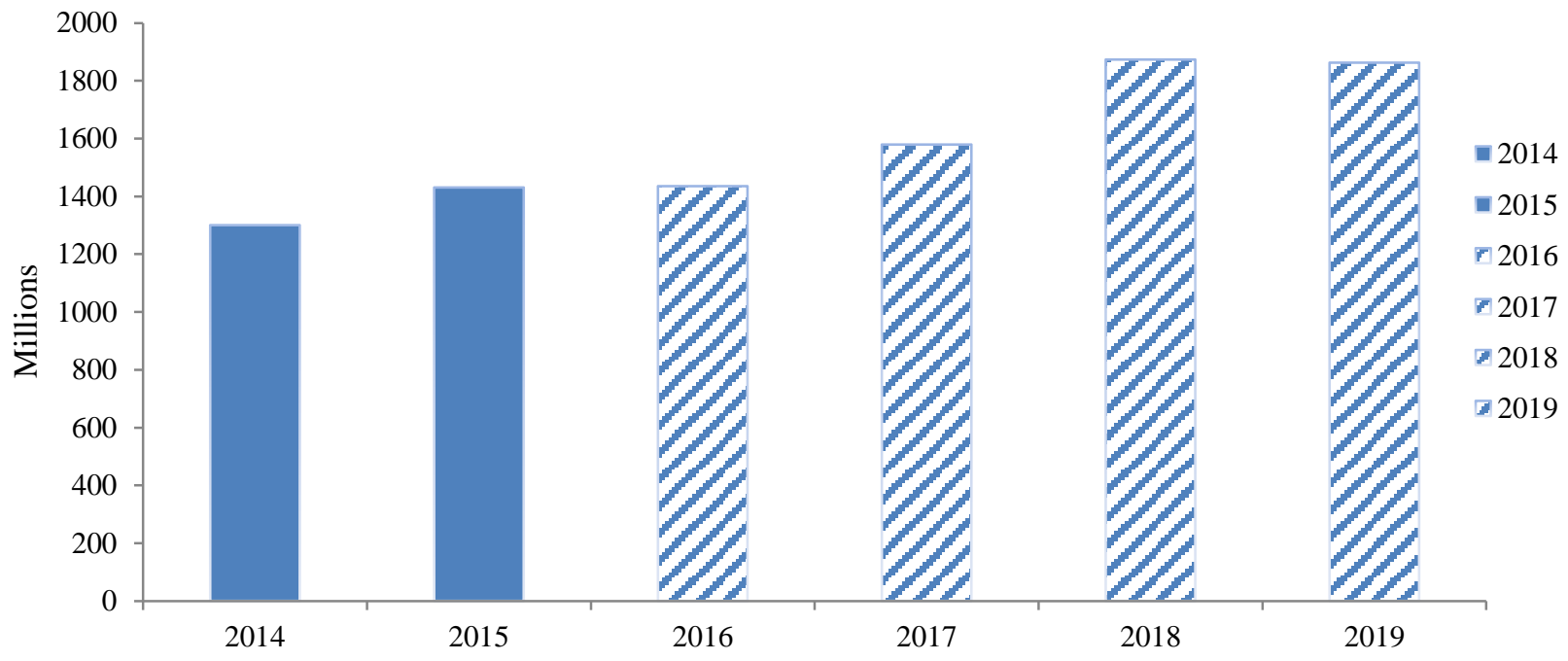

Fig. 4. According to smartphone shipment numbers of million devices were sold from 2014-215, and through smartphone shipment sold devices we further estimate that in future the number of sell device will be from 2016-2019 are shown in this graph

According to our critical analysis of different emergency applications in 2013-2014, 1300.4 million devices were sold from these devices $53 \%$ smartphones owners use their smartphones in emergency situations from 53\%; $45 \%$ smartphones were used for emergency applications to resolve emergency situations. From 2014-2015, 1429.8 devices were sold; from this ratio rate $60 \%$ smartphone owners use their smartphones in emergency situations, and from $60 \% ; 53 \%$ users use smartphones emergency applications in emergency situation, rest of the \%age inform contacts, so in 2015- 2016

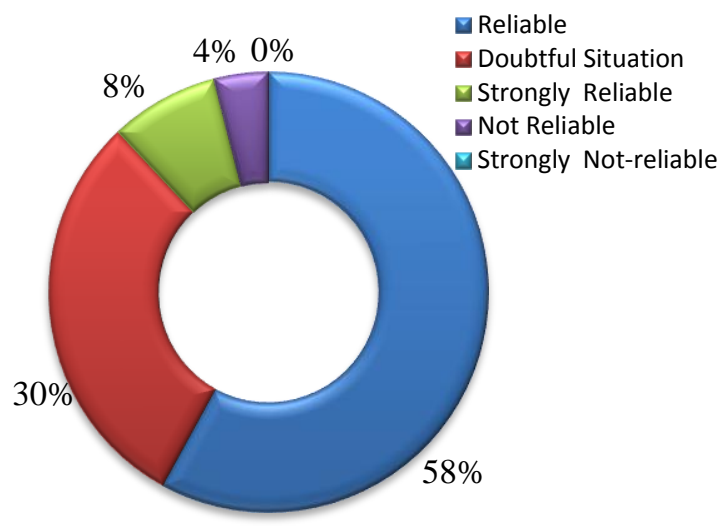

Fig. 3. Conducted in Japan 2013-2014 about the Survey Analysis of Emergency Applications

\section{FUTURE TRENDS OF SPSEM}

It is expected that more devices will be connected. We compare smartphone devices and smartphone emergency application users, and those users who do not use emergency applications but upload status and notifications on social media in case of any emergency situations. According to the smartphone shipment [51] in 2012, 6.8 Billion devices were sold, in 2013, 10 Billion devices were sold. We estimate these values and forecast the future in Figure 4. 
in 2018-2019 if 1862.3 million devices will be sold, from this $92 \%$ use smartphones devices in emergency situations, from
$92 \%$ 85\% will use emergency smartphones applications, this case is also shown in Figure 5.

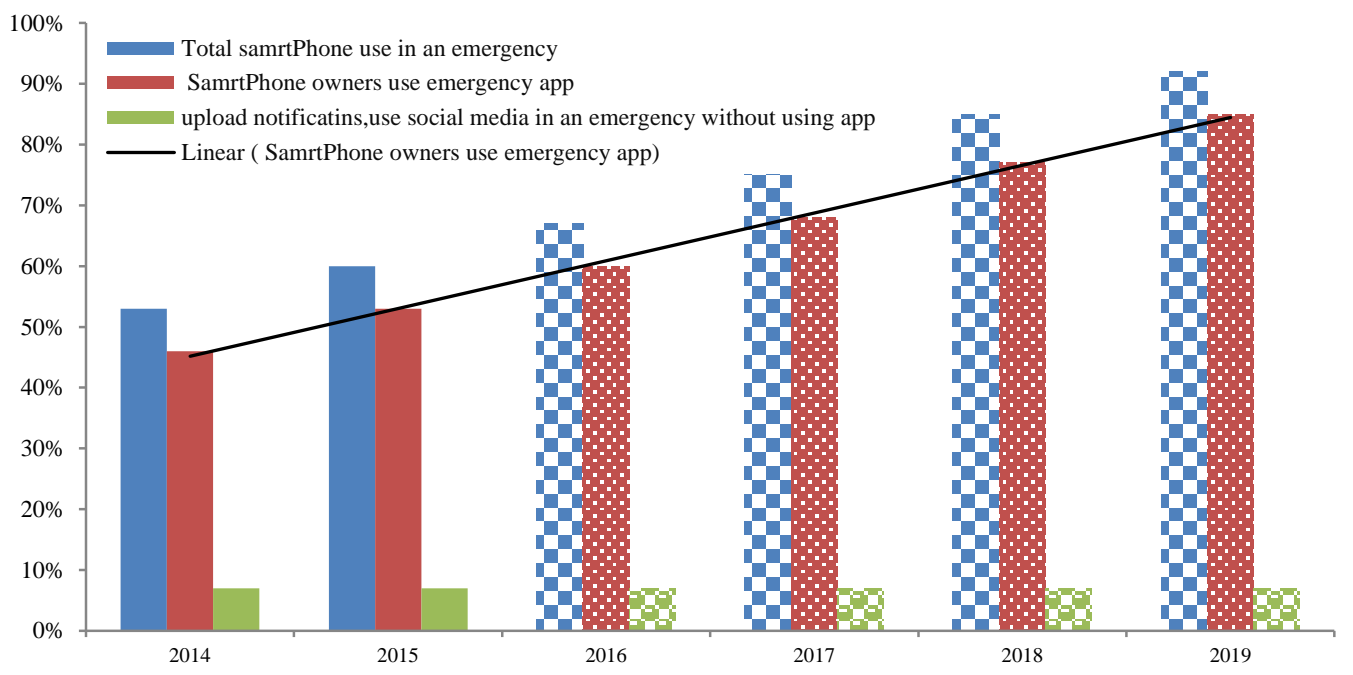

Fig. 5. From 53\% usage of smartphones emergency app we further estimate or analyze that in future how many users will use smartphone emergency or disaster app from 2016-2019

Smartphone performs or offers multiple functionalities such as GPS, multimedia services and because of continuously processing of different CPU tasks the smartphones have high power demands that makes the duration of battery very minimum. Once a battery of smartphone runs out no further operation can be performed on smartphones, and smartphone emergency or crisis applications can only work properly when application installed in a mobile device executes and also sensors are enabled in a smartphone like Bluetooth etc. Another major and important thing is that in natural disaster electric supply and telecommunication infrastructure may be destroyed that could results in weak or erratic signals. Smartphone will drain or evacuate excessive battery power to search or find constantly and continuously for signals. Hence optimal management of power supply and consumption is very critical and crucial and the most important factor is that in future web services, android, iOS developers must build any mechanism or emergency applications that when smartphone battery reaches up to $20 \%$ then task manager stops all running tasks except emergency applications and sensors, this type of solution overcome the battery drainage problem in disastrous situations.

\section{CONCLUSIONS}

In this paper, we have discussed how SPSEM works effectively in an emergency or disaster through embedded sensors and installed emergency applications. We highlighted many emergency applications and discussed how these emergency applications work in smartphone devices and how emergency applications detect disasters and directly report to the central website of emergency management via satellite GPS, and social media. Our goal is to highlight the features functions, capabilities and trends in SPSEM. We highlighted various functions and technology of emergency applications, at the end it could be suggested that everybody should install different emergency applications in smartphones because in case if you are in emergency then through emergency applications you can save yourself and other people.
We believe that the upcoming smartphones will be preloaded with emergency and disaster management applications. The designers of the operating systems for smartphones must strive for development and embedding of emergency management applications. Furthermore, these applications must be given access to full resources in a smartphone so that emergency could be dealt in an efficient manner. In future, we aim to investigate the performance issues and overheads that are associated with emergency management applications. We also aim to survey the users' attitude towards giving maximum rights and controls to these kind of applications to respond in emergency.

\section{REFERENCES}

[1] N. D. Lane, E. Miluzzo, H. L. D. Peebles, T. Choudhury, and A. T. Campbell, "A Survey of Mobile Phone Sensing," in IEEE Commun. Mag.,vol. 48(9), pp. 140-150, 2010.

[2] M. Mun, S. Reddy, K. Shilton, N. Yau, et al, "PEIR, the personal environmental impact report, as a platform for participatory sensing systems research", in Proceedings of the 7th international conference on Mobile systems, applications, and services, pp. 55-68, 2009.

[3] E. Miluzzo, N. D. Lane, K. Fodor, R. Peterson, H. Musolesi, S. B. Eisenman, X. Zheng, and A. T. Campbell, "Sensing meets mobile social networks: the design, implementation and evaluation of the cenceme application," in Proceedings of the 6th ACM conference on Embedded network sensor systems, 2008

[4] G. Chowdhury, H. Mridul and I. Kushchu, "Prospects of Using mTechnologies for Disaster Information Management in Bangladesh and other LDCs," EURO mGOV 2005, Brighton, UK, pp. 243-253.

[5] E. M. Patil, "Emergency Reporting Using Smartphone" 2013.

[6] F. Shih, O. Seneviratne, I. Liccardi, E. Patton, P. Meier, C.Castillo, "Democratizing mobile app development for disaster management", AIIP '13 Joint Proceedings of the Workshop on AI Problems and Approaches for Intelligent Environments and Workshop on Semantic Cities, Pages 39-42. 2013.

[7] Y. Baoquan "A Study of Smartphone Based Disaster Information Reporting System under Disaster Environment. International Journal of Smart Home" in International Journal of Smart Home, vol. 9, no. 1, pp. 45-52, 2015. 
[8] S. M. Taohidul Islam, Zamri Chik,"Disaster in Bangladesh and management with advanced information system", Disaster Prevention and Management: An International Journal, 2011

[9] S. Kate. "Digital Volunteerism During Disaster: Crowdsourcing Information Processing." Universityof Colorado, ATLAS Institute. $2011 . \quad<\quad$ http://crowdresearch.org/chi2011workshop/papers/starbird.pdf >.

[10] N. Eagle and A. Pentland, "Reality Mining: Sensing Complex Social Systems," Personal Ubiquitous Comp., vol. 10, no. 4, 2006, pp. 255268.

[11] Thompson, Kelli et al. "Social Media Experiment: Analysis Report Executive Summary." DHS Homeland Security Studies and Analysis Institute for DHS S\&T. 28 February 2014

[12] N. Dufty. "A review of the value of social media in countrywide disaster risk reduction public awareness strategies", in the Global Assessment Report on Disaster Risk Reduction" 2015

[13] B. McElveen. American Red Cross Annual Reort 2012 (http://www.redcross.org/images/MEDIA_CustomProductCatalog/m180 71523_Red-Cross-2012.AnnualReport.pdf)

[14] S. Thomas National Defense Magazine article "Social Media Changing the Way FEMA Responds to Disaster", September 2013

[15] T. E. White,"The Application of Social Media in Disasters" 2014

[16] J. Landgren, "Shared use of information technology in emergency," in Proceedings of the Second International ISCRAM Conference pp. 3541, 2005, Brussels, Belgium.

[17] T. Schoenharl, G. Madey, G. Szab’o, A. Barab’asi" WIPER: A MultiAgent System for Emergency Response ", 2006

[18] A. Al-Akkad, A. Zimmermann "Involving Civilians by Smart Phones During Emergency Situations," in ISCRAM Conference, 2011.

[19] P. Haddawy, L. Frank, "Situation Awareness in Crowd sensing for Disease Surveillance in Crisis Situations Singapore".2015.

[20] L. Frommberger and F. Schmid, "Mobile4D: Crowdsourced Disaster Alerting and Reporting", In Proceedings of the Sixth Int'l Conf. on Information and Communications Technologies and Development (ICTD '13), vol. 2. ACM.

[21] A. C. Palen, (2012). Social Media and Emergency Management.

[22] G. Schall1 and J. Sebastian, "VIDENTE- 3D visualization of underground infrastructure using handheld augmented reality" in GeoHydroinformatics: Integrating GIS and Water Engineering, 2010.

[23] D. Kalkofen, E. Mendez and D. Schmalstieg "Interactive Focus and ContextVisualization in Augmented Reality," Proc. 6th IEEE International Symposium on Mixed andAugmented Reality (ISMAR'07), pp. 191-200, 2007

[24] G. Schall, E. Mendez and D. Schmalstieg "Virtual Redlining for Civil Engineering". Proceedings of the 7th IEEE International Symposium on Mixed and Augmented Reality (ISMAR'08), 15-18 September 2008 Cambridge. IEEE.

[25] K. Mitra " A Mobile Cloud Computing for emergency management, "IEEE cloud computing published by the IEEE society, 2014

[26] D. Velev,P.Zlateva. "A Feasibility Analysis of Emergency Management with Cloud Computing Integration", International Journal of Innovation, Management and Technology, 2012

[27] R. Arden, (Aug. 26th, 2011) Surviving a natural disaster with cloud computing. Available: http://edocumentsciences.com/

[28] J. Therese B. Fajardo and M. Oppus" A Mobile Disaster Management System Using the Android Technology ",2009

[29] O. Mokryn, D. Karmi, A. Elkayam and T. Teller "Opportunistic Smart Rescue Application and System" The 11th Annual Mediterranean Ad Hoc Networking Workshop (Med-Hoc-Net), 2012
[30] L. J. White, C.Thompson, H.Turner, B. Dougherty, and D. C.Schmidt"WreckWatch: Automatic Traffic Accident Detection and Notification with Smartphones ".

[31] S. Rauscher, G. Messner, P. Baur, J. Augenstein, K. Digges, E. Perdeck, G. Bahouth, and O. Pieske. Enhanced Automatic Collision Notification System- Improved Rescue Care Due To Injury Prediction- First Field Experience, 2009.

[32] http://www.systemsensor.com/enus/documents/system_smoke_detectors_appguide_spag91.pdf

[33] K. Surachat, S. Kasikri W. Tiprat, and A. Wacharanimit, "First Aid Application on Mobile Device", International Scholarly and Scientific Research \& Innovation 7(5) 2013,pp-361-366.

[34] https://www.emv.vic.gov.au/our-work/victorias-warningsystem/fireready-app/

[35] CFA FireReady: Victorian Bushfire Information via Smart Phone (http://www.bushwalkingblog.com.au/cfa-fireready-victorian-bushfireinformation-via-smart-phone/).

[36] Official GreatCall Website. (2013, January). [Online]. Available: http://www.greatcall.com

[37] Earthquake-QuakeSOS (http://emergency20wiki.org/wiki/index.php/Smartphone_Apps)

[38] SAPER explosives detection (http://www.gizmag.com/saper-explosivesdetector-app/22614/.)

[39] C. Edwards "The Federal Emergency Management Agency Floods, Failures, and Federalism" November18, 2014

[40] Official ELERTS Website. (2013, January). [Online]. Available: http://elerts.com

[41] C. Thompson, J. White, B. Dougherty, A. Albright, and D. C. Schmidt, "Using Smartphones to Detect Car Accidents and Provide Situational Awareness to Emergency Responders" in International Conference on Mobile Wireless Middleware, Operating Systems, and Applications. pp. 29-42, 2012.

[42] O. Mokryn, D. Karmi, A. Elkayam and T. Teller "Help Me: Opportunistic Smart Rescue Application and System" The 11th Annual Mediterranean Ad Hoc Networking Workshop (Med-Hoc-Net), 2012.

[43] L. Bartel, V. Walle, G. Eede, and W. Muhren, "Humanitarian Information Management and Systems, Mobile Response" Second International Workshop on Mobile Information Technology for Emergency Response pp. 29-38, 2008,

[44] L. Bigley, L. K. Zachariah, M. Everett, "CCTV camera site selection: a field experience", 6th International VNIS. "A Ride into the Future", pp.21-27, 2015.

[45] S. Challa, "Patient Data Viewer: An Android application for healthcare", in Proc. 2011 Annual IEEE India Conference, India, 2011, pp. 1-4.

[46] http://www.smh.com.au/digital-life/digital-life-news/fireready-appupgraded-just-weeks-after-release-20140108-30gl9.html

[47] http://emergency20wiki.org/wiki/index.php/Smartphone_Apps

[48] https://itunes.apple.com/au/app/fema/id474807486?mt=8

[49] Calloway, L. J. and P. G. W. Keen. Organizing for crisis response. Journal of Information Technology 11,1 (2009) 13-27.

[50] http://www.pewinternet.org/2015/04/01/chapter-two-usage-andattitudes-toward-smartphones/.

[51] UNISDR. "Survey Analysis Report:the survey on persons with disability and disasters "Living with Disability and Disasters" Japan 2013.

[52] Global smartphone shipments forecast http://www.statista.com/statistics/263441/global-smartphone-shipmentsforecast/ 